\title{
EVALUATION OF PLUMBAGIN AS A POTENTIAL THERAPEUTIC AGENT FOR MURINE SCHISTOSOMIASIS MANSONI
}

\author{
By \\ EMAN E. A. METWALY ${ }^{1 *}$, SAEDIA A. SAYEDEL-AHL ${ }^{1}$, SOHEIR S. MAHMOUD ${ }^{2}$ \\ and DOAA A. AHMED ${ }^{1}$
}

Department of Medical Parasitology, Faculty of Medicine Al-Azhar University for Girls $^{1}$, Nasr City and Theodor Bilharz Research Institute ${ }^{2}$, Imbaba, Giza, Egypt

( ${ }^{*}$ Correspondence: dr.eman_ezzat@yahoo.com)

\section{Abstract}

Schistosomiasis still one of the major health problems worldwide, affecting millions of people in economically challenged tropical and subtropical countries of the world. Currently the treatment of schistosomiasis relies on a single anti-parasitic drug praziquantel; however it was found it is not fully effective and the potential for development of resistant to praziquantel has justified the research for new alternative chemotherapies especially from natural sources.

The current study evaluated the anti-parasitic effect of plumbagin against $S$. mansoni infected mice either alone or in combination with praziquantel through, parasitological parameters (worm load, oogram pattern, liver and intestine egg load) and histopathological parameters (granuloma number and diameter). Plumbagin showed a significant reduction in total worm burden $(P<$ $0.05)$, increase in dead eggs in oogram pattern and reduction in tissue ova count. Mean hepatic granulomas number and diameter were decreased with elevation in percentage of degenerated ova, compared to control group. Results were improved when praziquantel was used in combination with plumbagin as no male or coupled worm were detected, no immature ova and highly significant reduction in tissue egg load in liver and intestine $(P<0.001)$ compared to infected control group.

Key words: Schistosoma mansoni, Praziquantel, Plumbagin.

\section{Introduction}

Nowadays, schistosomiasis is the $3^{\text {rd }}$ most devastating tropical disease globally (after malaria and intestinal helminthic parasites) and is a major cause of morbidity and mortality for African Developing Countries especially under privileged communities (Gouveia et al, 2019). It affects over 799 million patients mostly children who are at risk of contracting infection (WHO, 2018). Schistosomiasisis is potentially life-threatening disease with sever gastrointestinal tract and hepato-splenic system manifestations (Neghina et $a l, 2009$ ), and incriminated as a major risk factor for many types of cancers as hepatic cancer and colorectal cancer (Osada et al, 2005).

Praziquantel (PZQ) is the drug of choice for treating all schistosomes and the only available drug documented for control programs (Doenhoff et al, 2008). Despite PZQ efficacy against all forms of schistosemes with mild and transient side effects, it has poor efficacy against juvenile forms as well as metabolism, genotoxicity and mutagenic effect (Vale et al, 2017). Besides, massive and exclusive reliance on a single drug raised legitimate concern about schistosome PZQ-resistance (Greenberg, 2013). So, there was an urgent need to develop new safe and effective drugs either acting alone or in combination with PZQ to combat development of resistant schistosomes strains and minimise PZQ drawbacks (El Ridi and Tallima, 2013; Hegazy et al, 2018)

The use of herbal products for improving one's health has been increased greatly in recent years. Indian medicinal plants provide a rich source of such products. Thus, there were many increasing efforts to develop new anti-schistosomal drugs mainly from plants sources; as herbs biological active materials without or minimal side effects (Magalhaes et al, 2014; Tu et al, 2019).

Plumbagin (5-hydroxy-2-methyl-1,4-naphthoquinone) is a natural quinonoid compound derived from the roots of many plants, especially sub-scandent shrubs of Plumbago spe- 
cies and used as a traditional medicine to treat gastrointestinal disorders as anti-flatulence, appetite stimulant and skin diseases (Padhye et al, 2012). Besides, plumbagin (PL) has potent anti-oxidant, antimicrobial, anti-inflammatory and anti-neoplastic effects against various cancer cells (Lorsuwannat et al, 2013; Tripathi et al, 2019). PL is pharmacologically considered safe agents with minimal side effects (Goveia et al, 2018).

This study aimed to evaluate the plumbagin effect on $S$. mansoni infected mice by parasitological and histopathological parameters.

\section{Materials and Methods}

Experimental design: Eighty male Swiss Albino pathogen-free mice, strain CD1, weighing 18-20gm and 6-8 weeks old were divided into the following groups:

Control groups: GI: (normal control group) mice; neither infected nor treated.

GII: (drug control group) received drugs but not infected were divided into three subgroups: GII-i: received PZQ orally in a dose of $500 \mathrm{mg} / \mathrm{kg} /$ day for 2 consecutive days. GII-ii: received PL orally in a dose of $8 \mathrm{mg} /$ $\mathrm{kg} /$ day for 3 consecutive days for 2 weeks, and GII- iii: received PL orally in a dose of $4 \mathrm{mg} / \mathrm{kg} /$ day for 3 consecutive days for 2 weeks and PZQ orally in a dose of 500 $\mathrm{mg} / \mathrm{kg}$ /day for 1 day as combined therapy.

GIII: (infected control group): infected with Egyptian strain of $S$. mansoni cercariae (60 10 /mouse) by subcutaneous injection.

GIV: received the treatment 6 weeks postinfection and divided into the following 3 subgroups: GIV-i: received PZQ orally as dose of $500 \mathrm{mg} / \mathrm{kg} /$ day for 2 consecutive days. GIV-ii: received PL orally in a dose of $8 \mathrm{mg} / \mathrm{kg} /$ day for 3 consecutive days for 2 weeks. GIV-iii: received PL orally in a dose of $4 \mathrm{mg} / \mathrm{kg} /$ day for 3 consecutive days for 2 weeks \&PZQ orally in a dose of $500 \mathrm{mg} / \mathrm{kg} /$ day for 1 day.

Laboratory bred male, Swiss albino mice of CDI strain, were used. The experimented with animals were dealt with according to the international valid guidelines, Theodor
Bilharz Research institute (TBRI), Egypt. Mice were infected subcutaneously in a dose of $60 \pm 10$ cercariae/mouse (Peters and Warren, 1969).

Drug administration: Drugs were given 6 weeks post-infection to detect the effect of the drugs on the mature worms as in this period the worms mature and start laying eggs that result in granuloma formation (Doenhoff et al, 2008).

Praziquantel (PZQ): Tablets (Distocide ${ }^{\circledR}$, EIPICO, Egypt) were administered orally as a suspension in 2\% Cremophore-El (SigmaAldrich Chemical Co, St. Louis, MO). The drug was given orally in a dose of $500 \mathrm{mg} /$ $\mathrm{kg}$ body weight for two consecutive days (Sabry et al, 2004) using esophageal tube

Plumbagin (PL): was purchased from Sigma Aldrich Chemical Company St. Louis, Mo, USA. It was given as $8 \mathrm{mg} / \mathrm{kg} 3$ times /week for two weeks (Wei et al, 2015). Scarification \& porto-mesenteric perfusion: All mice were sacrificed ten weeks postinfection by decapitation without anesthesia to avoid hepatic shift of worm and separation of copula due to anesthesia paralytic effect on worm musculature.

S. mansoni worm burden: Hepatic and porto-mesenteric vessels were perfused. Then, numbers and sex of the worms (males, females, \& couples) were determined (Duvall and Dewitt, 1967). The reduction in numbers of worm after treatment was calculated (Tendler et al, 1986).

Oogram pattern: After perfusion, the small intestine of each mouse was separated and transferred to a petri dish. Three fragments of small intestine were cut longitudinally, rinsed in saline, and slightly dried on filter paper. Fragments were examined and percentages of immature, mature, and dead eggs were identified and counted by the categories defined (Pellegrino et al, 1962).

Tissue egg load: Number of eggs per gram of tissue was estimated by weighing a piece of liver or small intestine, which was then digested and incubated overnight in $5 \% \mathrm{KOH}$ and number of eggs/gm intestine and liver 
was calculated (Cheever, 1968).

Histopathological study: Liver was removed from all mice, washed by normal saline and plotted with filter paper. Liver specimens were fixed at $10 \%$ buffered formalin and embedded in paraffin blocks. The prepared sections were examined by light microscopy using haematoxylin and eosin stains.

Granuloma numbers and diameters in liver sections: Haematoxylin and eosin (H\&E) stained liver sections were examined to count number and measure diameter of hepatic granulomas (Bancroft and Stevens, 1975).

Statistical analysis: Data were collected, tabulated, and analysed by (Statistical Package for Social Sciences (SPSS) version 18. Quantitative date was expressed as mean \pm SD (standard deviation). $\mathrm{P}$ value was considered significant if was less than 0.05 , highly significant if $P$ value was less than 0.001 and non-significant if it was more than 0.05 .

\section{Results}

Worm burden: PZQ treated group showed highly significant reduction in all worms. Combined therapy (PL and PZQ) showed an extremely significant reduction in male and female worm burdens.

Oogram pattern: PZQ showed significant elevation in the percentage of dead ova, with significant reduction of the percentage of the immature and mature ova compared with infected control group (Tab. 2).

Hepatic tissue egg load: There was a reduction in ova count in hepatic tissue of the infected treated groups; PZQ, Plumbagin and combined when compared with infected untreated control group (Fig. 3). The reduction in hepatic tissue egg load in PZQ, Plumbagin and combined infected treated mice 6 weeks post-infection was $81.25 \%, 80.6 \%$ $\& 90.9 \%$ ), respectively compared with infected controls with highly significant difference $(\mathrm{P}<0.001)$.

Intestinal tissue egg load: There was a reduction in ova count in intestinal tissue of the infected treated groups; PZQ, Plumbagin and combined when compared with infected control group. Reduction in intestinal tissue egg load in PZQ, Plumbagin and combined infected treated groups was, $(79.7 \%, 75 \%$ \& $91.9 \%$ ) respectively compared with infected untreated control group with high significant difference $(\mathrm{P}<0.001)$.

Stained liver sections showed reduction in mean granuloma number in PZQ, Plumbagin and combined infected treated groups was $(66 \%, 62.5 \% \& 88 \%)$ respectively with high significant difference $(\mathrm{P}<0.001)$ compared with infected untreated group. The reduction in mean granuloma diameter in PZQ, Plumbagin and combined infected treated groups was $(30 \%, 23 \% \& 32.5 \%)$, respectively with statistical significant difference $(\mathrm{P}<0.001)$ compared with infected control group.

The reduction in hepatic granuloma number and diameter in combined treated group was higher than PZQ treated group (Tab. 4).

The details were given in tables $(1,2,3 \&$ $4)$ and figures $(1,2,3,4 \& 5)$.

Table 1: Effect of PZQ, PL \& combined on mean male, female \& coupled burden \& reduction compared to infected control

\begin{tabular}{|l|c|c|c|c|c|c|c|c|}
\hline $\begin{array}{c}\text { group } \\
\text { Infected mice }\end{array}$ & $\begin{array}{c}\text { Male } \\
(\mathrm{MWB})\end{array}$ & $\begin{array}{c}\text { Red } \\
(\%)\end{array}$ & $\begin{array}{c}\text { Female } \\
(\mathrm{FWB})\end{array}$ & $\begin{array}{c}\text { Red } \\
(\%)\end{array}$ & $\begin{array}{c}\text { Couples } \\
(\mathrm{CWB})\end{array}$ & $\begin{array}{c}\text { Red } \\
(\%)\end{array}$ & $\begin{array}{c}\text { Total } \\
(\mathrm{TWB})\end{array}$ & $\begin{array}{c}\text { Red } \\
(\%)\end{array}$ \\
\hline Control & $2.43 \underline{2.13}$ & ---- & $1.88 \pm 0.72$ & --- & $3.14 \pm 1.68$ & --- & $9.43 \pm 1.99$ & ---- \\
\hline PZQ treated & $0.36 \pm 0.11$ & 85.18 & $0.4 \pm 0.15$ & 78.72 & $0.18 \pm 0.02$ & 94.26 & $1.12 \pm 0.3$ & 88.12 \\
\hline PL treated & $0.71 \pm 1.01 *$ & 70.78 & $0.6 \pm 0.04$ & 68.08 & $0.29 \pm 0.49 * * *$ & 90.8 & $1.89 \pm 2.03$ & 79.96 \\
\hline PL+PZQ treated & $0 * * *$ & 100 & $0.14 \pm 0.38^{* * *}$ & 92.5 & 0 & 100 & $0.14 \pm .38^{* * *}$ & 98.5 \\
\hline
\end{tabular}

*Significant difference from infected control $(P<0.05)$. ${ }^{* * *}$ Significant difference from infected control $(P<0001)$.

Table 2: Egg stages\% (immature, mature and dead) in PZQ, PL \& both compared to infected controls.

\begin{tabular}{|c|c|c|c|}
\hline \multirow{2}{*}{ Infected mice } & \multicolumn{3}{|c|}{$\%$ Egg developmental stages } \\
\cline { 2 - 4 } & Immature ova $\%$ & Mature ova\% & Dead ova\% \\
\hline Infected control & 47.5 & 44.43 & 8.7 \\
\hline PZQ treated & $1.8^{* * *}$ & $5.5^{* * *}$ & $92.7^{* * *}$ \\
\hline PL treated & $22.5^{*}$ & $35^{*}$ & $42.5^{*}$ \\
\hline PL+PZQ treated & $0^{* * *}$ & $5.43^{* * *}$ & $94.57^{* * *}$ \\
\hline
\end{tabular}


Table 3: Reduction of tissue egg load in mice treated with PZQ,PL, and both comparison to infected controls

\begin{tabular}{|c|c|c|c|c|}
\hline \hline Parameters & Liver & $\begin{array}{c}\text { Red } \\
(\%)\end{array}$ & $\begin{array}{c}\text { Intestine } \\
(\%)\end{array}$ \\
\hline Infected control & $39888.9 \pm 3892$ & & $29333.33 \pm 2619.37$ & \\
\hline PZQ treated & $6777.78 \pm 109.72^{* * *}$ & 83 & $5944.44 \pm 917.93^{* * *}$ & 79 \\
\hline PL treated & $7750 \pm 1058.04 * * *$ & 80.75 & $7333.33 \pm 950.15^{* * *}$ & 75 \\
\hline PL+PZQ treated & $3638.778 \pm 1889.75^{* * *}$ & 91 & $2388.89 \pm 727.61 * * *$ & 91.9 \\
\hline
\end{tabular}

Red (\%):percent of egg reduction.

Table 4: Reduction of mean hepatic granuloma number \& diameter in S. mansoni infected mice treated with PZQ, PL \& both.

\begin{tabular}{|l|c|c|}
\hline $\begin{array}{c}\text { Parameters } \\
\text { Infected mice }\end{array}$ & $\begin{array}{c}\text { \% Reduction in } \\
\text { granuloma number }\end{array}$ & $\begin{array}{c}\text { \% Reduction in } \\
\text { Granuloma diameter }\end{array}$ \\
\hline ZQ treated & $66.31 \%$ & $29.92 \%$ \\
\hline PL treated & $62.59 \%$ & $23.13 \%$ \\
\hline PL+PZQ treated & $88.18 \%$ & $32.6 \%$ \\
\hline
\end{tabular}

Discussion

Praziquantel becomes a less potent drug (Fakahany et al, 2014). Consequently, the parasites that escaped the first treatment and matured after it are also responsible for recorded cases of PZQ failure, and therapeutic effect on them may be achieved by a second treatment with PZQ with more drug side effects (El-Feky et al, 2015), with development parasite resistance against PZQ (Tawfeek et al, 2019). Plumbagin exhibits many highly potent biological activities as an antioxidant, anti-inflammatory, anticancer, antibacterial and antifungal agents (Padhye et al, 2012), as well as its capable of inhibiting the drug efflux mechanism in drugresistant bacteria, thereby allowing intracellular accumulation of potent drug molecules, also induces oxidative stress in parasites (Lorsuwannarat et al, 2013).

The present study showed a strong impetus of the in vivo Plumbagin anti-schistosomal activity and enhanced praziquantel activity by combination to treat schistosomiasis.

The present parasitological results of infected mice treated with PZQ showed highly significant reduction in male, female, couples and total worm burden. Although, PL when used in treatment showed significant reduction in male, female, couples and total worms indicating that PL negatively affected male and couples more than females that could be due to disturbance of adult worm tegument, which in schistosomes is a vital target to resist drugs due to its exposure to the hosts' fluid of drug used. The anthelmintic nature of the drug was explained by
Zhang and Coultas (2013), through in vitro studies reported that this phenomenon was due to damage in males including abnormalities in their tegument and musculature with disturbance in gynaecophoric canal, signifying the decreased efficacy of males in holding the females stable in their canal. The presence of highly folded surface, tubercles, and also the large gynaecophoric canal may be responsible for more drug absorption. Worthwhile, using combined therapy (PZQ $\&$ PL) showed more highly significant worm reduction up to $100 \%$ in male and couples while only few females were detected. This result highlights the expectation of oogram results and tissue egg load in the studied groups. As oogram provides a simple, sensitive, and reliable criterion for the screening of drugs infected control group activity against $S$. mansoni, reduction of im-mature eggs at the oogram pattern indicating an early interruption of egg laying process due to affection of female genital system or ova itself (Abdul-Ghani et al, 2010).

As to the oogram pattern in infected mice treated with PZQ showed highly significant reduction of immature ova and elevation in percentage of dead ova compared with PL showed significant reduction of percentage immature and mature ova. This reduction in viable egg numbers may be due to death of adult female worms. Also, PL treated mice showed elevation of dead ova when compared with the infected control group. Such changes indicate possible lethal effect of PL on released eggs in the lumen of intestine.

However, when PL combined with PZQ 
there were no immature ova detected and highly significant decrease in the mature ova and elevation of the percentage of dead ova (5.4\% and $94.5 \%)$, respectively compared with infected untreated control group and the drugs alone, this alterations in the oogram revealed success of combined therapy to interrupt the processes of oviposition and egg development as well as on maturation and survival of eggs trapped in the intestinal mucosa. Thus, combined therapy exhibited an ovicidal activity on eggs already laid in the intestinal wall.

In the present study, PZQ showed high reduction percentage in hepatic and intestinal tissue egg load, which was slightly higher than PL alone compared with infected control. But, combined PL \& PZQ had the highest effect in this aspect. The combination of PL \& PZQ at lower concentrations translated into potent anti-schistosomal activity that could be attributed to adults death and obstructing the oviposition process by increasing the dead eggs.

The present results agreed with Aly et al. (2010) who found that after oral treatment of PZQ at a dose of $500 \mathrm{mg} / \mathrm{kg}$ body weight for 2 consecutive days a week 6 post-infection, PZQ showed high reduction in worm burden (95.6\%). where the oogram pattern showed complete disappearance of all immature ova from the wall of the intestine with reduction in number of mature ova, and significant elevation of dead ova to $(95.8 \%)$, as well as the hepatic and intestinal tissue egg load (95.7\% \& 96.4\%, respectively).

In the present study; PZQ showed high percentage of reduction in TWB $(88.12 \%)$, with significant elevation of dead ova (92.7\%), compared with the control group, and the hepatic and intestinal tissue egg load (83\% \& $79 \%$, respectively). It was worthy to report that tworm reduction percentages in mice infected and treated by PL is the first recorded as no available recorded studies about in vivo effect of PL on number of worm load or tissue distribution could be and thus less severe pathogenicity.
Lorsuwannarat et al. (2013) found that 91$100 \%$ of worms after $24 \mathrm{~h}$ were killed that went with the present results.

The hydroxynaphthoquinones compounds, including PL, can act as CoQ antagonists by being electrons acceptor in completion with CoQ in anelectron transport chain (Srinivas et al, 2004; Babula et al., 2007). Schistosomes are known to be one of few parasites that produce at least one-third of its energy by aerobic process, using CoQ as electron carriers between respiratory complexes (Masuma et al, 2009). Thus, the PL schistosomicidal action linked to the ability to compete with CoQ in electron transport chain.

Surviving in man, schistosomes are challenged by reactive oxygen species (ROS) gene-rated by different mechanisms in the parasite as well as by activated host immune cells. It has been shown that the parasite at schistosomula stage were killed by host immune cells through an antibody-dependent cell mediated cytotoxicity in which host white cells (e.g., eosinophils) generate ROS (e.g., superoxide anions \& hydroxyl radicals) through an oxidative burst to kill the parasites (Loverde,1998). Thus, PL has the schistosomicidal action through generating the ROS (Dzoyem et al, 2007).

Alternatively, there was suggestion that PL may cause cytotoxicity via semi quinone radical production and ROS generation. The increasing of ROS \& $\mathrm{H}_{2} \mathrm{O}_{2}$ thus deplete glutathione reserve by oxidizing GSH to GSSG, thus affecting the parasites' ability to protect themselves from the free radicals (Padhye $e t$ al, 2012). Consequently, depletion of GSH reserve might be responsible for their death from PL treatment.

In schistosomiasis granuloma formation \& fibrosis is the corner stone of morbidity and mortality (Melo et al, 2011). Zuim et al. (2012) reported that the greater the number of eggs and worms the more number of granulomas recorded in tissues. So, in this study, low granulomas in liver indicated decrease in number of eggs in liver. 
The present results showed that the PL convergent results with PZQ in reduction of granulomas number and diameter, whereas PZQ \& PL combined therapy was superior to each drug alone. This agreed with Shaha et al. (2017). These present result may be attributed to its protective effect against liver damage by inhibiting inflammation, cellular infiltration, collagen and cytokine production, This agreed with Wang et al. (2016) who reported that PL was a potential therapy for hepatic diseases associated with fibrosis and angiogenesis, hopeful in protecting from advanced serious complications.

Cytokines are important regulators of immune-inflammatory responses and play effective role in regulation of granuloma formation and fibrosis. Hoffmann et al. (2002) reported the alteration in $\mathrm{T}$ helper cytokine profiles during the formation of granulomatous reaction. The transforming growth factor-betal (TGF- $\beta 1)$ is a fibrosis potentiation Th2 cytokine, also, a good indicator for hepatic fibrosis, via activation and differentiation of Hepatic stellate cells (HSCs) that stimulates the fibroblast proliferation (Massagué, 2012). Wang et al. (2016) recorded that PL has anti-fibrotic effect via down-regulation of TGF- $\beta 1$. Wei et al. (2015) found that PL may be the alternative anti-fibrotic medication due to its hepato-protective and anti-fibrotic effect shown by improvement of mice general conditions and increased body weight also by reduction of elevated liver enzymes and inflammatory cytokines and attenuation of collagen deposition in liver, as abnormal expressions of collagen markers were lower in the presence of PL.

\section{Conclusion}

The present study showed that PL especiallly when combined with PZQ could improve $S$. mansoni induced liver damage, as it showed extremely reduction of worm burden and significant decrease in the number of intact mature eggs accompanied by increase in number of dead eggs and reduction of the deposited eggs in tissues with decrease in the granuloma number and diameter. It could be considered as a new therapeutic candidate for treatment of schistosomiasis and provide basis for experimental and clinical trials.

\section{Acknowledgement}

The authors deeply appreciated the support given by Dr.Tarek Aboushousha, Professor of Pathology, Theodor Bilharz Research Institute, Imbaba, Giza, Egypt.

\section{References}

Abdul-Ghani, R, Loutfy, N, Sheta, M, Hassan, A, 2010: Efficacy of low-dose myrrh protocols in the treatment of experimental schistosomiasis mansoni: hepatic improvement without parasitologic cure. Res. Rep. Trop. Med. 1:65-71.

Andrade, ZDA, 2009: Schistosomiasis and liver fibrosis. Parasite Immunol. 31, 11:656-63.

Atjanasuppat, K, Wongkham, W, Meepowpan, P, Kittakoop, P, Sobhon, P, et al, 2009: In vitro screening for anthelmintic and antitumour activity of ethnomedicinal plants from Thailand. J. Ethnopharmacol. 123, 3:475-82.

Babula, P, Adam, V, Havel, L, Kizek, R, 2007: Naphthoquinones and their pharmacological properties. Ceska a Slovenska farmacie: casopis Ceske farmaceuticke spolecnosti a Slovenske farmaceuticke spolecnosti. 56, 3:114-20. Bancroft, J. D, Stevens, A, 1975: Histopatholo gical Stains and Their Diagnostic Uses. Churchil living stone. Edunberg; New York.

Cheever, AW, 1968: Conditions affecting the accuracy of potassium hydroxide digestion techniques for counting Schistosoma mansoni eggs in tissues. Bull. WHO 39, 2:32-8.

Doenhoff, MJ, Cioli, D, Utzinger, J, 2008: Praziquantel: mechanisms of action, resistance and new derivatives for schistosomiasis. Curr. Opin. Infect. Dis. 21, 6:659-67.

Duvall RH, De Witt WB, 1967: An improved perfusion technique for recovering adult schistosomes from laboratory animals. Am. J. Trop. Med. Hyg. 16, 4:483-6.

Dzoyem JP, Tangmouo, JG, Lontsi, D, Etoa, FX, Lohoue, PJ, 2007: In vitro antifungal activity of extract and plumbagin from the stem bark of DiospyroscrassifloraHiern (Ebenaceae). Phytother. Res. 21:671-4.

El Ridi, RA, Tallima, HA, 2013: Novel therapeutic and prevention approaches for schistosomiasis. J. of Adv. Res. 4, 5:467-78.

Gouveia, MJ, Brindley, PJ, Gärtner, F, Costa, JM, Vale, N, 2018: Drug repurposing for schist- 
osomiasis: Combinations of drugs or biomolecules. Pharmaceut.11, 1:15-9.

Gouveia, MJ, Brindley, PJ, Rinaldi, G, Gärtner, F, da Costa, JMC, et al, 2019: Combination anthelmintic/antioxidant activity against Schistosoma mansoni. Biomolec. 9, 2:54-8.

Melo, G, Sponchiado, J, Machado, A, Cáceres, N, 2011: Small-mammal community structure in a South American deciduous Atlantic Forest. Commun. Ecol. 12, 1:58-66.

Hegazy, LAM, Al Motiam, MH, El-Aal, NF A, Ibrahim, SM, Mohamed, HK, 2018: Evaluation of artesunate and praziquantel combination therapy in murine schistosomiasis mansoni. Iran. J. Parasitol. 13, 2:193-7.

Hoffmann, A, Levchenko, A, Scott, ML, Baltimore, $D$, 2002: The I $\mathrm{B}-\mathrm{NF}-\kappa \mathrm{B}$ signaling module: Temporal control and selective gene activetion. Science 298, 5596:1241-5.

Huang, HH, Rigouin, C, Williams, D, 2012: The redox biology of schistosome parasites and applications for drug development. Curr. Pharm. Des. 18, 24:3595-611.

LoVerde, PT, 1998: Do antioxidants play a role in schistosome host-parasite interactions? Parasitol. Today 14, 7:284-9.

Lan, HY, Chung, AC, 2012: TGF-b/Smad signalling in kidney disease. Semin. Nephrol. 32, 3: 236-43.

Kita, K, Hirawake, H, Miyadera, H, Amino, H, Takeo, S, 2002: Role of complex II in anaerobic respiration of the parasite mitochondria from Ascaris suum and Plasmodium falciparum. Biochim. Biophys. Acta (BBA)-Bioenergetics, 1553, 1/2:123-9.

Lorsuwannarat, N, Saowakon, N, Ramasoota, P, Wanichanon, C, Sobhon, P, 2013: The anthelmintic effect of plumbagin on Schistosoma mansoni. Exp. Parasitol. 133, 1:18-27.

Lorsuwannarat, N., Piedrafita, D., Chantree, P., Sansri, V., Songkoomkrong, S., et al, 2014: The in vitro anthelmintic effects of plumbagin on newly excysted and 4-weeks-old juvenile parasites of Fasciola gigantica. Exp. Parasitol. 136:5-13.

Magalhães, LG, Machado, CB, Morais, ER, de Carvalho Moreira, ÉB, Soares, CS, et al, 2009: In vitro schistosomicidal activity of curcumin against Schistosoma mansoni adult worms. Parasitol. Res. 104, 5:1197-201.

Massagué, J, 2012: TGF $\beta$ signalling in context. Nat. Rev. Mol. Cell Biol, 13, 10:616-30.
Masuma, R, Shiomi, K, Ōmura, S, 2009: Helminth electron transport inhibitors produced by fungi. In: Physiology and Genetics. Springer, Berlin, Heidelberg.

Melo, G, Sponchiado, J, Machado, A, Cáceres, N, 2011: Small-mammal community structure in a South American deciduous Atlantic Forest. Commun. Ecol. 12, 1:58-66.

Neghina A, Merkler C, MarincuI, Moldovan, R, Iacobiciu, I, 2009: Intestinal schistosomiasis, importation of a neglected tropical disease in Romania: Case report of a traveler to endemic regions. Travel Med. Infect. Dis. 7:49-51.

Osada, Y, Kumagai, T, Masuda, K, Suzuki, T, Kanazawa, T, 2005: Mutagenicity evaluation of Schistosoma spp. extracts by the umu-test and V79/HGPRT gene mutation assay. Parasit. Int. 54, 1:29-34.

Padhye, S, Dandawate, P, Yusufi, M, Ahmad, A, Sarkar, FH, 2012: Perspectives on medicinal properties of plumbagin and its analogs. Med. Res. Rev. 32,1 6:1131-58.

Pellegrino, J, Oliveira, CA, Faria, J, Cunha, AS, 1962: New approach to the screening of drugs in experimental schistosomiasis mansoni in mice. Am. J. Trop. Med. Hyg., 11,1 2:201-15. Peters, PA, Warren, KS, 1969: A rapid method of infecting mice and other laboratory animals with Schistosoma mansoni: Subcutaneous injection. J. Parasitol. 55, 3:558-63.

Sabry HY, Hassan, SI, Mahmd SH, Ezzat A R, Fahmy Z.H, 2004: Modification of resistance to reinfection with Schistosoma mansoni in mice by combined administration of praziquantel and non-steroidal anti-inflammatory drugs. Egypt J. Med. Sci. 25:839-59.

Shah, KK, Pritt, BS, Alexander, MP, 2017: Histopathologic review of granulomatous inflammation. J. Clin. Tubercul. Mycobact. Dis. 7:112.

Srinivas, P, Gopinath, G, Banerji, A, Dinakar, A, Srinivas, G, 2004: Plumbagin induces reactive oxygen species, which mediate apoptosis in human cervical cancer cells. Mol. Carcinog.: Published in cooperation with the University of Texas MD Anderson Cancer Center, 40, 4:20111.

Tendler, M, Pinto, RM, Oliveira, LA, Gebara, G, Katz, N. (1986): Schistosoma mansoni: Vaccination with adult worm antigens. Int. J. Parasitol.16, 4:347-52.

Tripathi, SK, Panda, M, Biswal, BK, 2019: 
Emerging role of plumbagin: Cytotoxic potential and pharmaceutical relevance towards cancer therapy. Food and Chem. Toxicol. 125:566-82.

Tu, J, Guo, Y, Hong, W, Fang, Y, Han, D, et al, 2019: The regulatory effects of Paeoniflorin and its derivative Paeoniflorin-6'-O-benzene sulfonate CP-25 on inflammation and immune diseases. Front. Pharmacol. 10, 57.

Vale, N, Gouveia, MJ, Rinaldi, G, Brindley, P J, Gärtner, F, et al, 2017: Praziquantel for schistosomiasis: single-drug metabolism revisited, mode of action, and resistance. Antimicrobial. Agents Chemothe. 61, 5:e2582-16.

Wang, H, Zhang, H, Zhang, Y, Wang, D, Cheng, $X$, et al, 2016: Plumbagin protects liver against fulminant hepatic failure and chronic liver fibrosis via inhibiting inflammation and collagen production. Oncotarget, 7, 50:82864-75.

Wei, Y, Huang, M, Liu, X, Yuan, Z, Peng, Y, et al, 2015: Anti-fibrotic effect of plumbagin on

\section{Explanation of figures}

Fig. 1: Effect of PZQ, PL and combined treated group on worm reduction\% (male, female, coupled and total worms).

Fig. 2: Oogram pattern in $S$. mansoni infected mice treated with PZQ, PL \& both compared to infected controls. Fig. 3: Reduction of tissue egg\% load in S. mansoni infected mice treated with PZQ, PL and combined treated groups.

Fig. 4: Reduction \% of hepatic granuloma number and diameter in S. mansoni infected mice treated with PZQ, PL \& both treated groups.

Fig. 5: A- Light photomicrograph of a liver section of S. mansoni-infected, non-treated mouse showing a large granuloma with a trapped egg, accumulation of inflammatory cells surrounding granuloma with large peripheral zone of Inflammatory cells and disorganization of hepatic strands B- Light photomicrograph of a liver section of PZQ treated mice showing medium sized granuloma with starting ova degeneration and a peripheral zone of Inflammatory cells, with disorganization in hepatic strands. C- Light photomicrograph of a liver of PL treated mice showing granuloma with trapped egg, accumulation of inflammatory cells surrounding the granuloma, with disorganization in the hepatic strands. D- Light photomicrograph of a liver of combined treated $S$. mansoni- infected mice showing a remarkably reduced sized granuloma with complete ova degeneration and less inflammatory cells (H\& E, X200).
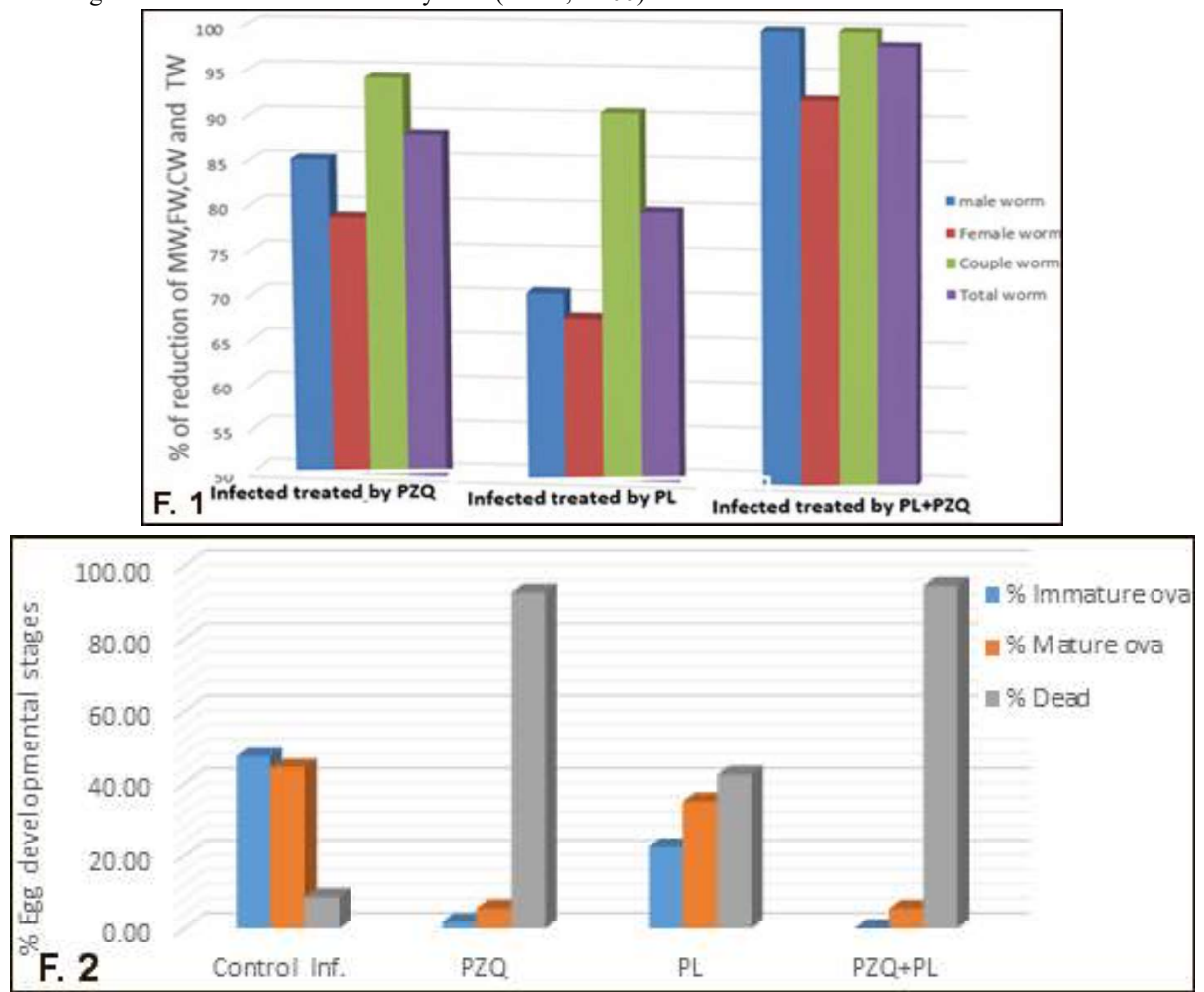

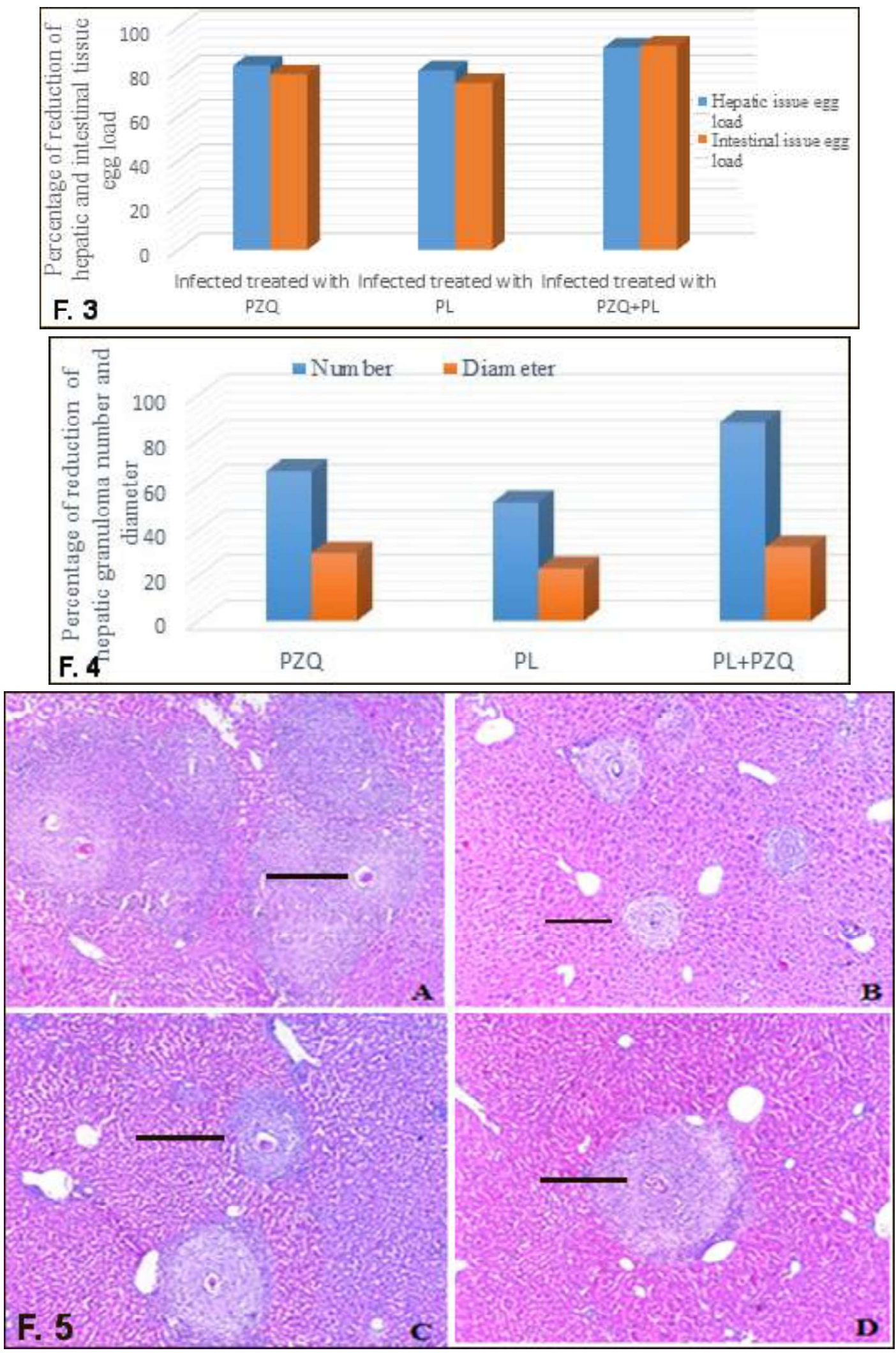